\title{
Adaptation to vertical displacement of the visual direction'
}

\author{
HANS WALLACH AND JEROME H. KRAVITZ ${ }^{2}$ \\ SWARTHMORE COLLEGE
}

\begin{abstract}
Sixty Ss wore vertically displacing wedge prisms and adapted by looking at their feet for $10 \mathrm{~min}$. Half of them did this while standing and the others in supine position. The latter condition produced adaptation measurable with a visual-motor test and with a test of egocentric localization, but on a purely motoric test no adaptation was apparent. Standing during the adaptation period produced no effect.
\end{abstract}

Adaptation to displaced visual direction, usually produced by wearing wedge prisms, has been obtained under two kinds of conditions. Either $\mathrm{S}$ looks at his surround or at one of his own limbs. In the latter case the issue has arisen whether the limb to which $S$ pays attention during the period of adaptation must be moved or whether it may remain stationary. With the arm the inspected limb, Held and Hein (1958) found the former to be true, whereas Wallach, Kravitz, and Lindauer (1963), whose Ss adapted while looking at their legs, obtained adaptation with Ss remaining immobile. The different results may be due to the fact that, in the case of a standing $\mathrm{S}$, the legs normally coincide with the gravitational vertical and are being visually displaced by the prism out of this direction while there is no such distinctive position for the arm. This interpretation is supported by the fact that, when their Ss adapted in supine position, Wallach, Kravitz, and Lindauer did not obtain an adaptation using the kind of test employed by Held and Hein.

Since, with $\mathbf{S}$ in the supine position, laterally displacing prisms shifted the apparent direction of the legs in the horizontal plane, no directional change relative to the vertical took place. By using a vertically displacing prism that changes the visual direction of the legs relative to the vertical also when $S$ is in supine position, we expected to obtain an adaptation. Such an outcome would support our interpretation of the results of Wallach, Kravitz, and Lindauer.

Three types of tests have been previously used to measure adaptation to displaced visual direction. In the pointing tests (Ptg) S marks the location of a visual target or points at it with an outstretched arm under conditions where the pointing limb is invisible and thus cannot be visually lined up with the target direction. The visual target direction is motorically expressed, and could therefore also measure an adaptive change in kinesthetic or postural perception. This is the type of test used by Held and Hein, and it yielded adaptation only when the inspected arm actively moved. In the second type of test, $S$ indicates the direction that appears to him as straight ahead, by turning himself on a rotating chair until a visual target point appears to be straight ahead (Held \& Bossom, 1961), by directing $E$ in moving a luminous point in the dark until it appears straight ahead (Wallach, Kravitz, \& Lindauer), or by turning a projector until a small spot it casts on the wall is shifted into a position where it appears straight ahead (Rock, Goldberg, \& Mack, 1966). This forward direction test (FD) does not require $S$ to make bodily movements directly related to a visual direction. Neither does it deal with an objective target location; the final target position defines a distinctive egocentric direction. The third type of test combines features of the previous two: In the dark, $\mathrm{S}$ is required to point his arm straight ahead (Harris, 1963). In this forward pointing test ( $\mathrm{F} \quad \mathrm{Ptg})$ a motor response is used to express a distinctive egocentric direction.

The different types of test do not always give the same result for one and the same adaptation condition. Shaffer and Wallach (1966) obtained effects in the same amount with a Ptg and a F Ptg test and a smaller adaptation with a FD test when Ss adapted to a laterally displacing prism by walking for $1 / 2 \mathrm{~h}$. Wallach, Kravitz, and Lindauer, in addition to a Ptg test, employed an FD test to measure adaptation to $10 \mathrm{~min}$ of viewing one's legs through a laterally displacing prism. When Ss stood during adaptation, effects of the same amount were obtained by the Ptg and the FD test. In the supine condition the FD test yielded large adaptation, while the Ptg test, as already stated, failed to measure any. We can offer no interpretation of this difference.

The present experiment in which Ss in supine position adapted to vertically displacing prisms and were tested with all three types of tests had a twofold purpose: to verify the prediction derived above that vertical displacement would yield an adaptation measurable with a Ptg test, and to contribute further evidence that active movement of the inspected limb is not always necessary. Wallach, Kravitz, and Lindauer did measure adaptation with a Ptg test for stationary Ss, but they were standing and it may be argued that maintaining this posture requires small corrective movements that satisfy the reafference hypothesis from which Held and Hein made their prediction, this docs not apply to the supine position. Actually four groups of $15 \mathrm{Ss}$ each were used in the present experiment, two adapting to an upward or downward displacing prism in supine position and in ofter two while standing.

\section{PROCEDURE}

Prisms of 30-diopter strength were used. One prism face was covered with a Wratten Filter 58 to diminish color dispersion and thus restore sharpness of all contours. The prisms were inserted in the opening for the right eye of welder's goggles, one with the base up, and the other base down. S's left eye was occluded throughout the experiment. Adaptation training consisted in viewing one's feet for $10 \mathrm{~min}$, either standing or lying on a daybed with the head raised and supported by pillows. There were four groups of 15 Ss. Thirty Ss were trained with upward displacing prisms and 30 adapted to downward displacement; half of these went through adaptation training standing, the other in supine position.

The three types of tests previously discussed were used. All were made in the dark and with the prism goggles removed. S was always standing upright, his head position fixed by a teeth mold. The target for the Ptg test was a luminous horizontal line, $10 \times .5 \mathrm{~cm}$. A vertical board extending forward from S's chest between his head and his right shoulder prevented his pointing right hand from moving too much to the left and obscuring the target. A vertical scale mounted on the far edge of this board permitted reading the position of S's pointing finger after he had made his response.

With the prism displacement vertical, the FD test became a test of horizontal direction. Here $\mathrm{E}$ moved the target line slowly up or 
Table 1

Mean Adaptation Effects in Degrees Obtained for Three Tests

\begin{tabular}{|c|c|c|c|c|}
\hline \multicolumn{2}{|r|}{ Conditions of adaptation training } & \multicolumn{3}{|c|}{ Type of test } \\
\hline Position of $\mathrm{S}$ & Direction of displ. & Pointing to target & Horizontal direction & Horizontal pointing \\
\hline supine & up & $3.30 \mathrm{p}<.001$ & $1.70 \mathrm{p}<.02$ & $.50 \mathrm{p}>.5$ \\
\hline supine & down & $3.60 \mathrm{p}<.02$ & $4.75 \mathrm{p}<.001$ & $-.40 \mathrm{p}>.9$ \\
\hline standing & up & -.05 & -.02 & $.70 \mathrm{p}>.6$ \\
\hline standing & down & $1.00 \mathrm{p}>.3$ & $1.68 \mathrm{p}<.01$ & $1.40 \mathrm{p}>.2$ \\
\hline
\end{tabular}

downward until S judged it to be at the level of his eyes. A single FD test was the average of two such settings, one where $\mathrm{E}$ moved the line down from a vertical position that was clearly too high, and another one where the line was moved up from a point below the horizontal. No standard procedure in moving the line was necessary since $\mathrm{E}$ could not influence the outcome of this test; he was unable to see the position of the line in the dark until a setting was completed and he read the target position with a flashlight.

In the F Ptg test $S$ stood in total darkness and was asked to raise his right arm so that his finger pointed to an invisible target at the level of his eyes. $\mathrm{S}$ kept his arm in that position until $\mathrm{E}$ again read the position of his finger. In this, as well as in the other pointing test, the vertical board prevented $S$ from seeing his raised arm when the flashlight was turned on.

These three tests were given twice, before and after the training period. Their order was F Ptg, Ptg, FD, training period, FD, Ptg, F Ptg.

\section{RESULTS}

The effect of adaptation was computed for each $S$ in each kind of test as the difference between the pointing direction-or the direction of the average setting of the target line-before the training period and the same measures taken after training. The mean difference scores for the four experimental conditions and the three kinds of tests are listed in Table 1. Mean differences that represent changes in the direction of adaptation are represented by positive numbers; the p-values given are for two-tailed tests.

The results support our expectation that the supine training would produce adaptation measurable with a Ptg test when vertically displacing prisms were used; an effect on pointing at a target was obtained that matched in magnitude the effect measured with the FD test. The results of the F Ptg test did not seem to reflect an adaptation effect. This fact, however, cannot be established because variance is large. This would be important, because adaptation to prismatic displacement produced under different training conditions had yielded the same effect in Ptg and F Ptg tests (Harris, 1963; Shaffer \& Wallach, 1966). It is, however, possible to show that in our experiment the results of the two tests, rather than being the same, differ significantly. For the combined groups of Ss undergoing adaptation in supine position, the mean adaptation effects obtained with the Ptg and the F Ptg test showed a mean difference of $3.5 \mathrm{deg}$ which was significant at the .01 level on a two-tailed test. This result precludes for the case of vertical displacement a familiar interpretation of adaptation measured with a Ptg test, namely, that adaptation consists in an altered evaluation of postural stimulation.

That no adaptation was obtained when $S$ was in an upright position during training was entirely unexpected. This result calls for further investigation. It should, however, be emphasized that the supine training condition, where $\mathrm{S}$ was completely passive, produced adaptation, whereas the standing condition, in which he had to maintain his equilibrium with small corrective movements, did not.

\section{REFERENCES}

HARRIS, C. S. Adaptation to displaced vision: Visual, motor or proprioceptive change? Science, 1963, 140, 812-813.

HELD, R., \& BOSSOM, J. Neonatal deprivation and adult rearrangement: Complementary techniques for analyzing plastic sensory-motor coordinations. Journal of Comparative \& Physiological Psychology, 1961, 54, 33-37.

HELD, R., \& HEIN, A. V. Adaptation of disarranged hand-eye coordination contingent upon re-afferent stimulation. Perceptual \& Motor Skills, 1958, 8, 83-86.

ROCK, I., GOLDBERG, J., \& MACK, A. Immediate correction and adaptation based on viewing a prismatically displaced scene. Perception \& Psychophysics, 1966, 1, 351-354.

SHAFFER, O., \& WALLACH, H. Adaptation to displaced vision measured with three tests. Psychonomic Science, 1966, 6, 143-144.

WALLACH, H., KRAVITZ, J. H., \& LINDAUER, J. A passive condition for rapid adaptation to displaced visual direction. American Journal of Psychology, 1963, 76, 568-578.

\section{NOTES}

1. The work was supported by a grant from the National Science Foundation.

2. Address: Department of Psychology and Education, Swarthmore College, Swarthmore, Pennsylvania 19081, and Department of Psy chology, Howard University, Washington, D. C. 20001.

(Accepted for publication January 16, 1969.) 